\title{
Publisher Correction: Conductivity control via minimally invasive anti-Frenkel defects in a functional oxide
}

Donald M. Evans (D), Theodor S. Holstad, Aleksander B. Mosberg (D), Didrik R. Småbråten (D), Per Erik Vullum, Anup L. Dadlani D, Konstantin Shapovalov, Zewu Yan, Edith Bourret, David Gao, Jaakko Akola, Jan Torgersen (D), Antonius T. J. van Helvoort, Sverre M. Selbach (D) and Dennis Meier (D)

Correction to: Nature Materials https://doi.org/10.1038/s41563-020-0765-x, published online 17 August 2020.

In the version of this Article originally published, in Fig. $3 c$ the label 'O $1 s \rightarrow \mathrm{O} 2 p-\mathrm{Er} 5 d$ ' was incorrect; it should have read 'O( $1 s)$ $\rightarrow \mathrm{O}(2 p)-\operatorname{Er}(5 d)-\mathrm{Mn}(3 d)$ '. Also, the label 'O $1 s \rightarrow \mathrm{O} 2 p-\mathrm{Mn} 3 d$ ' should have been removed. The original and corrected versions of Fig. $3 \mathrm{c}$ are shown below.
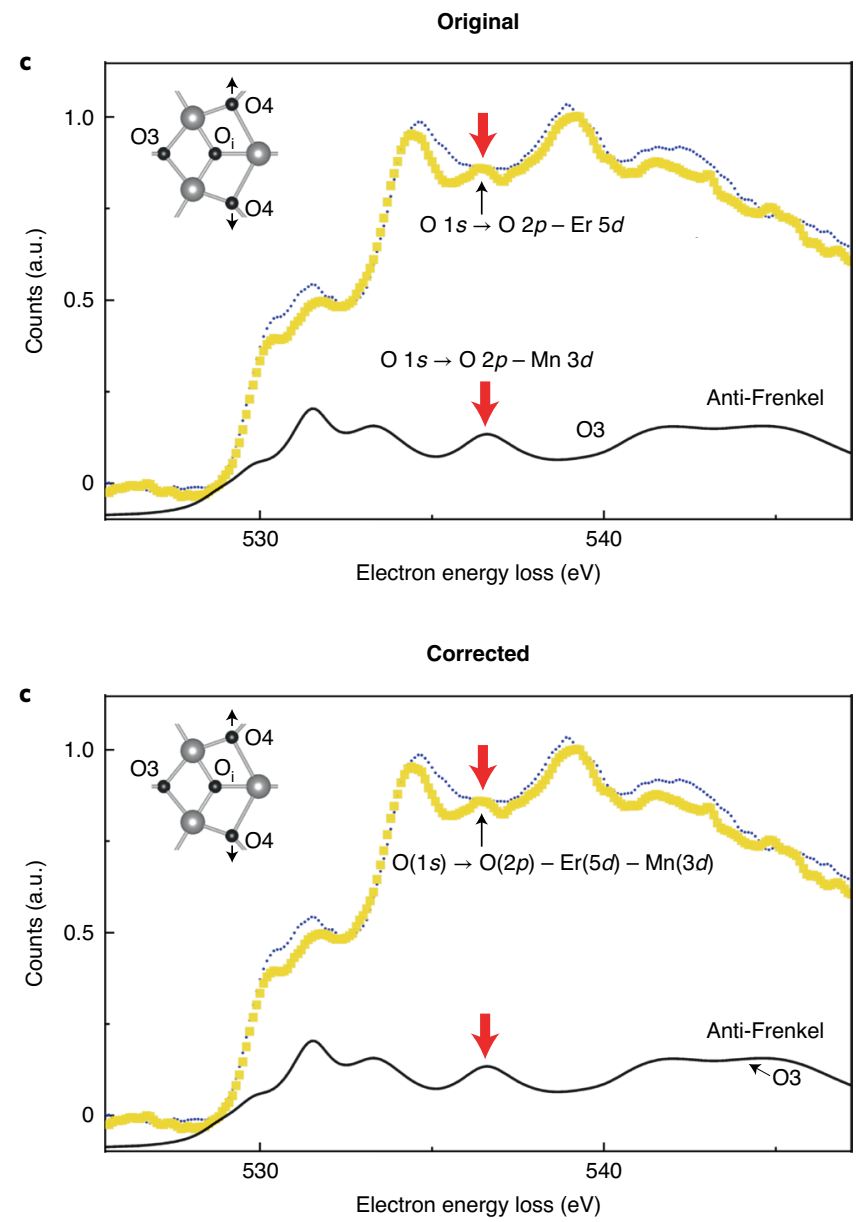

Fig. 3 | Original and Corrected.

Published online: 14 September 2020

https://doi.org/10.1038/s41563-020-00823-1

(C) The Author(s), under exclusive licence to Springer Nature Limited 2020 